\title{
SEISMIC SITE RESPONSE
}

\author{
P. E. Salt*
}

\section{INTRODUCTION}

It has long been recognized that the intensity of shaking in the epicentral region in a large earthquake is far from uniform. The common engineering approach has been to regard local site conditions as having paramount influence in the total response prediction problem. One particular site model, that of onedimensional wavetransmission, has been widely applied with varying degrees of success. Other theoretical site models have been proposed, and these tend to re-emphasize the very complex nature of the site response problem. Furthermore, recent research has indicated that local site effects may in fact be overshadowed by differences in source mechanism.

This paper provides a review of some recent literature on the site response problem. The author claims no original contribution to the material presented; rather the paper has been prepared to contrast the common belief among engineers that the problems of site response have been largely solved.

\section{SURFACE MOTION DUE TO EARTHQUAKES}

Studies of damage caused by earthquakes over the past century reveal a surprisingly irregular pattern of intense shaking within the epicentral region. Though damage to structures is not necessarily an indication of shaking intensity, that and other evidence seems to indicate marked variations in ground motions over distances of only half a kilometre or less. Such observations have encouraged research into problems broadly termed "microzonation studies". The complete solution to such a microzonation problem then, making the inherent assumption that the problems associated with nonuniform strong motion have been correctly identified, is to predict a time-history of surface motion tailor-made to a particular site. In practice a simplified solution is necessary, in which one pursues the more important parameters associated with damage to man-made structures, viz:-

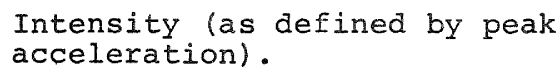

(ii) Frequency.

(iii) Duration.

Figure 1 (from Udwadia(1)) illustrates the nature of the total problem. Factors which influence the surface motion at a

\footnotetext{
* Assistant Engineer, Ministry of Works and Development. Formerly Graduate Research Assistant, Department of Civil Engineering, University of British Columbia, Vancouver, B.C., Canada.
}

particular point are :-

(i) The source mechanism, which seems to influence the frequency content and duration.

(ii) The materialproperties of the earth media through which the waves propagate, in the macro sense.

(iii) The nature and orientation of the various geological discontinuities (boundary conditions) in the wave paths.

(iv) Material properties and boundary conditions in the local region of the recording station as a separate factor.

It should be emphasised that the first three factors cover a scale of the order of tens of kilometres, while the fourth factor refers to a local region covering depths of the order of 300 metres and horizontal distances of less than several kilometres. Clearly in some approaches to the total surface motion problem this fourth factor, localized site conditions, need not be separately identified.

Engineering orientated research over the last decade has tended to concentrate on the last factor, the localized subsoil conditions. Two possible reasons have
been suggested for this emphasis (1) :-

(i) Local subsoil conditions are routinely determined in site investigations.

(ii) The popular analytical approach in modelling subsoil structure has been in familiar engineering terms, (the shear beam, lumped mass and finite element models).

Even should such a local site model be perfected, clearly it is unlikely to explain all strong motion effects. In the next section some of the shortcomings of the most popular engineering model, based on one-dimensional, body wave transmission are outlined and in the following section some of the less well known site response models are introduced.

\section{THE ONE-DIMENSIONAL SITE MODEL}

An 8 ft-quoted paper by Suzuki, published in $1932(2)$, stated that from observational studies in Japan the angle of incidence with the vertical of the initial motion of 51 earthquakes averaged $4^{\circ}$ at the surface, and tended to approach zero as the epicentral distance decreased from $25 \mathrm{~km}$ to zero. Now considering this low angle of incidence and applying the theory of plane waves, it is possible to envisage a one-dimensional base motion excitation. This has lead to an extensive series of theoretical models based on one-dimensional vertical plane 
propagation in which one is solving the wave equation

$$
c^{2} \frac{\partial^{2} U(z, t)}{\partial z^{2}}-\frac{\partial^{2} U(z, t)}{\partial t^{2}}=F(t)
$$

$U$ is the horizontal displacement and is a function of height $z$ above "base-rock" and time only. $C$ is the shear wave velocity in soil and $F(t)$ is some timevarying forcing function in the base rock. Boundary conditions initially were those of planar free surface in a homogeneous, linear elastic material. Lumped mass and finite element solutions are solution techniques developed to handle the more complex boundary value and material

inhomogeneity problems. Sometimes only the steady state, or a homogeneous solution was considered which introduces additional limitations in the applicability of this solution technique to the real situation.

Prominent in this field is the work of seed et al (13, 14 for example and many others) a great deal of which will be familiar to many readers and thus will not be discussed in detail. The one-dimensional model has been applied to suitable sites in Japan also.

Two particular applications of the onedimensional theory will be considered further. One is Mexico City, the other an unusual installation of bore-hole seismographs in Union Bay in Seattle.

Investigation of the motions recorded at Mexico City during strong earthquakes (5) seemed to indicate that the surface of the deep clay deposit was oscillating essentially at the natural period of the layer (approximately 2.5 seconds) as determined from a one-dimensional model. This prevalent ground period has been repeated in several earthquakes and the example of Mexico city is often quoted as a case where local site effects dominate, and in which onedimensional theory has been successfully applied. The evidence is by no means conclusive however.

Tsai and Housner (4) point out that where this dominant 2.5 second period is present the epicentral distances involved are relatively large. Thus it is possible that the soft lake "bowl" of Mexico City was responding primarily to the passage of horizontally travelling waves rather than vertically incident waves. A period of 2.5 seconds corresponds to a wave-length of approximately four kilometres which is sufficiently long for inphase excitation of a large mass of soil. On the other hand, had the natural period of the lake been very short, the corresponding short wave lengths may not have been strong enough at these epicentral distances (in excess of $250 \mathrm{~km}$ ) to produce appreciable excitation at the natural period.

A second point which suggests prediction of earthquake response may be difficult, concerns the material properties used in one Mexico City analysis. Herrera, Rosenblueth and Rascon (5) performed their analysis based on the usual soil mechanics approach in which soil properties determined from laboratory tests are used in a computerized mathematical analysis to obtain the theoretical spectra. In order to obtain the best correspondence between theoretical and recorded spectra, the soil properties obtained from geophysical exploration and laboratory tests required considerable adjustments.

The Union Bay installation in Seattle consists of three seismographs placed one above the other (Fig. 2, Table 1) in a borehole sunk through three layers of material. A number of investigators have used results obtained from this station to test various site analysis techniques. In particular Tsai and Housner (4) applied their theoretical one-dimensional model in order to compare theoretical surface records with those recorded. The actual recorded base motion was used as input. Two records were used; one was a small local earthquake, (March 1967), with maximum recorded acceleration of $0.0072 \mathrm{~g}$. This corresponds to shear strain of $1 \mathrm{x}$ $10^{-5}$, shear stress $0.345 \mathrm{kPa}$. The epicentre was 32 kilometres distant and focal depth about 32 kilometres. This situation is favourable to having nearly vertically incident shear waves. The second record was a strong microtremor background noise from a local storm. accelerations were about $0.0019 \mathrm{~g}$. It would appear from initial examination that the results are very good. (Fig. 3 - 11). However the authors' own comments on these results are revealing and are reproduced here.

"Although general agreement between computed and recorded clay motions is reasonably good which it should be as all the parameters were adjusted to give the best fit, there are still appreciable errors in the details of the motion. We feel that the agreement cannot be significantly improved by further adjustment of wave velocities or damping. The discrepancies, we think, result from the fact that the waves are not ideal vertically travelling, planar, shear waves, and that clay and till are not exactly planar. This conclusion is reinforced by the fact that 10 per cent of critical damping in the first mode was required to obtain the best agreement. At the very small levels of stresses and strains involved the effective viscous and hysteretic damping in the clay should be very small and, it is thought, could not account for the 10 per cent damping required in the first mode. If the actual motions are not caused by perfect vertically-travelling, planar, shear waves, extra modal damping will be required to account for energy lost from observation because of horizontal components of wave velocities. Allam (1969), on the basis of microtremor readings with arrays of instruments, concluded that waves of Love and Rayleigh types are prominent. In fact, the agreement between computed and recorded Union Bay motions is better than would be anticipated from Allam's work. There are surprisingly large differences between the amplification spectra of the earthquake and the microtremor, and the differences may be even larger for strong earthquake motions. 
"It is not known how accurately the surface motion could be calculated from recorded earthquake base motion for a more complicated layered system in which the total depth of layering is greater than under Union Bay and the free surface motion is not available for adjusting parameters."

Tsai (II) in his Ph.D. Thesis (1969), concludes that a good deal of care must be exercised in applying the then current onedimensional theory. Amongst his final conclusions were :-

Surface records of at least two earthquakes obtained at the same site are needed in order to see if local subsoils have a dominant effect.

(ii) Source mechanism plays an important role in determining ground spectra.

(iii) A site with well defined, soft subsoils is likely to produce reasonance effects of lower modes during a sufficiently long earthquake in which case the response spectra may be predictable and generally independent of the detailed characteristics of arriving waves.

\section{ALTERNATIVE APPROACHES}

Some alternative approaches to theoretical site response and the results they predict are now presented.

Trifunac (6) adopted as a theoretical model a semi-cylindrical valley on which incident $\mathrm{SH}$ waves impinged and were reflected at the surface, (Fig. 12). From this model he calculated a closed form solution for displacement spectra as a function of the angle of incidence of $\mathrm{SH}$ waves. Several qualitative results were obtained :-

(i) As the wave length $\lambda$ decreases, the presence of the cylindrical valley increases the effect on the free field motion. In other words, shorter wavelengths "feel" the effect of comparable size discontinuities in the surrounding strata.

(ii) For increasing wave velocity ratios $B / \beta_{V}$ i.e. softer material in the valley, the amplicification is increased.

(iii) For $\beta / \beta_{v}$ and density ratio $\rho / \rho_{V}>1$, there are many sections along the surface of the valley where significantly high local amplifications take place. These regions are not necessarily confined to the deepest part of the valley and apparently depend on $\beta / \beta_{V}, \rho / \rho_{V}$. "Shadow" and "Focusing" effects appear from rays passing through the semi circular lens.

(v) It is possible in this simplified case to have the formation of standing waves at certain points in the region. There also appear points of very rapid change of phase at the same time that displacement amplitudes are zero. This implies that some structures could be excited by predominantly torsional oscillations.

(vi) It appears that many local spectral peaks depend on $\gamma$, the angle of incidence and $x$, the position in the valley.

This suggests that unless direction of approach of the main disturbance and the detailed site geology are known, interpretations based on correlating observed spectral peaks to simple local models could be in error.

(vii) Comparison of the amplification pattern for the cases $r=a$ and the single horizontal layer model with layer depth $\mathrm{H}=$ a shows no simple correspondence in amplification pattern.

David M. Boore, (7) in a study of surface topography effects on incident $\mathrm{SH}$ waves found that there was amplification at all frequencies between base motion and crest motion of ridges, and deduced that for wavelengths of the order of surface topography, spatial distribution of strong motion is markedly affected by topography.

Trifunac,

(8) of an infinite shear wall resting on a semi-cylindrical rigid foundation. He found that waves scattered from the rigid foundation contributed significantly to the surface ground motion at least within distances of one order of magnitude greater than the characteristic length of the foundation.

In a forced vibration experiment on a nine story building by Jennings, radiated motions from the building were detected 6.7 miles away. This observation together with Trifunac's theoretical study indicate that the ideal of "free field" motion at a given site and thus a site response problem as such may not exist for the purposes of a soil model synthesis.

Jackson (10) using ray tracing theory examined the focusing effects of wave velocity inhomogenities and of irregular boundaries between base rock and upper layers, (Fig. 13 - 15). His results illustrate, again in a qualitative manner, how geological boundaries affect motion, and cause local surficial irregularities in intensity.

The above-mentioned site models all consider the spatial effects of reflecting and refracting body waves at boundary discontinuities. The results are essentially qualitative but they do illustrate the errors that can be introduced in an oversimplified site model.

Trifunac (12), in a study of a number of strong motion records however showed that the problem of site response is even more complex than solution of the body wave problem. Using response spectra as narrow pass filters he showed that surface wave motion for near, shallow earthquakes makes a significant contribution especially in the period range of damaging structural response. This is further evidence that the total source/transmission pattern cannot be ignored in favour of local site effects.

Another recent paper by Sakurai Kurihara and Takahashi (15) contains 
evidence which indicates that ground motion varies in phase at least within distances of less than 30 metres, a degree of detail which is not normally considered in site response studies. Clearly there is still a lot more information to be obtained from instrumental studies of strong motion.

\section{SOURCE MECHANISM INFLUENCE}

Inherent in the one-dimensional approach to the site response problem is the assumption that the "base rock" motion is some sort of uniform wide band disturbance and that the interesting properties (from the engineering point of view) are largely the result of the wave transmission through the final few hundred feet of surface layers. There is ample evidence to discredit this over-simplistic view. Certainly it would appear that source mechanisms can have a considerable effect. Udwadia (I) studied the $16 \mathrm{~S} . \mathrm{M}$. records obtained at the USCGS station at El Centro. Richter magnitudes ranged from $3-6.7$ and epicentral distances were mostly less than $100 \mathrm{~km}$. These included a number of earthquakes which were assigned the same epicentre. The summary of his results were :-

(i) The earthquake source cannot be modelled as a broad band process. Smaller earthquakes seem to have a relatively higher frequency content when transmission path and epicentral distances are held constant.

(ii) Multiple events are quite different in nature from single event earthquakes. There is a relatively higher content of high frequency in multiple events.

(iii) Surface wave energy is important for distant large earthquakes. It influences the duration of shaking and also contains significant amplitudes at around the 1 second period, the period range of many man-made structures.

(iv) The nature of records at the one station obtained from different azimuths seems different. The phases do not arrive at the same relative times, causing the response of the structure located at a site to be strongly dependent on the direction of the approach of the waves.

(v) The spectra of vertical components show generally broader band content than corresponding spectra of horizontal components.

(vi) There is very poor correlation between spectral peaks predicted for the site using one-dimensional wave theory and those actually obtained from the various records.

It may be appropriate at this point however to introduce the orders of magnitude of site material properties before completely dismissing site effects. El Centro has shear wave velocities ranging from $6400 \mathrm{~m} / \mathrm{sec}$ (base rock) to $1800 \mathrm{~m} / \mathrm{sec}$ over depths of the order of 5000 - 6000 metres. The "base rock" at Mexico City (5) is believed to lie at a depth of about 500 metres and has a shear wave velocity of $2800 \mathrm{~m} / \mathrm{sec}$ while the intervening soft clay has velocities ranging from $1080 \mathrm{~m} / \mathrm{sec}$ to as low as about $50 \mathrm{~m} / \mathrm{sec}$. The Union Bay site in Seattle was dealing with depths of only tens of metres and shear wave velocities from $500 \mathrm{~m} / \mathrm{sec}$ to $70-150$ $\mathrm{m} / \mathrm{sec}$.
Two other examples of the uncertainty surrounding site-source effects are presented.

Tsai (11) gives an example of the noticeable effect of source mechanism. The Borrego Mountain Earthquake of 9 th April 1968 was recorded at San onofre, about $138 \mathrm{kilometres}$ from the epicentre and assigned a Richter Magnitude 6.5. This earthquake was unusual in that it consisted of two separate shocks 6 seconds apart which apparently originated from the same source. As can be seen from Fig. 16 18 the spectra are quite different. The possibility exists however that on a more susceptible recording site, these differences may have been minimised.

Gutenberg

tudied small earthquak ground motions around Pasadena recorded by sensitive vibration meters located on various thicknesses of alluvium overlying base rock. From this study he formulated some general conclusions on the pattern of strong motion in the area. Hudson (17) repeated the study after the San Fernando earthquake and found that the strong motion patterns did not agree with those found in Gutenberg's study. In some cases Hudson found larger motions on rock than on alluvium, the reverse of Gutenberg's findings.

Strong motion instrument arrays, especially in Southern California have been steadily improved over the years and with recent earthquakes have produced a great deal of information on near field ground motion which in turn contains detailed information about the source mechanism. This information is often lost in the attenuation and dispersion effects present in teleseismic records. The currently accepted description of the earthquake source is that of the sudden release of strain energy from a finite region by slippage or shearing on a fault plane; strain energy which has previously accumulated very slowly.

It may be possible that such a shallow earthquake source can be characterized by two or three parameters, whose values can be determined or satisfactorily estimated prior to an earthquake. Thus with an accurate picture of the source mechanism, the wave transmission problem may prove to be insignificant, or at least more tractable, to rational solutions.

\section{CONCLUSIONS}

The site response problem is still a long way from complete resolution. In particular the one-dimensional body wave solutions, even when fully refined, will not solve the total problem. The engineering approach places undue emphasis on this small aspect of the site response problem to the detriment of attempts to obtain a full understanding of the complete problem. Scepticism is in order over claims to have solved the problems of damage variation using a one-dimensional body wave approach. Such claims must be evaluated carefully for a genuine capability of prediction, rather than mere explanation of a single event. Furthermore, some doubt must be cast by the available 
evidence on the importance of the local subsoil conditions in affecting surface motion as distinct from damage to structures thereon.

\section{REFERENCES}

(1) Udwadia F. E. "Investigation of Earthquake and Microtremor Ground Motions", EERL 72-02, California Institute of Technology, Pasadena.

(2) Suzuki $T$. "On the Angle of Incidence of the Initial Motion Observed at Hongo and Mitaka", Bulletin of the Earthquake Research Institute, University of Tokyo, Vol. X 1932.

(3) Trifunac M. D., "Response Envelope Spectrum and Interpretation of Strong Earthquake Ground Motion", Bulletin of the Seismological Society of America, Vol. 61, 2, pp 343-356 April 1971.

(4) Tsai N. C. and Housner G. W. , "Calculation of Surface Motions of a Layered Half-Space", Bulletin of the Seismological Society of America, Vol. 60, 5 October 1970.

(5) Herrera I., Rosenblueth E., , Rascon O.A. "Earthquake Spectrum Prediction for the Valley of Mexico", Proceedings 3rd World Conference on Earthquake Engineering Vol. I pp I-6I-174 (1965).

(6) Trifunac M. D. "Surface Motion of a Seimi-Cylindrical Alluvial Valley for Incident Plane SH Waves" Bulletin of the Seismological Society of America, Vol. 61, 6 December 1971 .

(7) Boore, David M., "A Note on the Effect of Simple Topography on Seismic SH Waves" Bulletin of the Seismological Society of America Vol. 62, 1 February 1972.

(8) Trifunac M. D., "Interaction of a Shear Wall with the Soil for Incident Plane SH Waves" "Bulletin of the
Seismological Society of America, Vol. 62, 1 February, 1972.

(9) Jennings P. C., "Distant Motions from a Building Vibration Test", Bulletin of the Seismological Society of America, Vol. 60, 6 December, 1970.

(10) Jackson P. S., "The Focusing of Earthquakes" Bulletin of the Seismological Society of America, Vol. 61, 3 June, 1971 .

(11) Tsai N. C., "Influence of Local Geology on Earthquake Ground Motion", Ph.D. Thesis, 1969 California Institute of Technology, Pasadena.

(12) Trifunac M. D.," "Response Envelope Spectrum and Interpretation of Strong Earthquake Ground Motion", Bulletin of the Seismological Society of America, Vol. 62, 2 April, 1971.

(13) Seed H. B., and Idriss I. M. "Analysis of Ground Motion at Union Bay, Seattle During Earthquakes and Distant Nuclear Blasts", Bulletin of the Seismological Society of America Vol. 60, 1 February 1970.

(14) Seed, Whitman, Dezfulian, Dobry, Idriss, "Soil Conditions and Building Damage in the 1967 Caracas Earthquake" Journal A.S.C.E. Soil Mechanics Division, Vol. 98 SM 8 August 1972.

(15) Sakurai A., Kurihara C., Takahashi T., "A Proposal for Earthquake Response Analyses of Long Structures and Aseismic Design Criteria of Pipelines", Proceedings 5th World Earthquake Engineering Conference, Rome 1973.

(16) Gutenberg B. " "The Effects of Ground on Earthquake Motion", Bulletin of the Seismological Society of America, Vol. 47 pp 221-251 1957.

(17) Hudson, D. E., "Local Distribution of Strong Earthquake Ground Motion" Bulletin of the Seismological Society of America Vol. 62, 6 December 1972.

TABLE 1

MEASURED SUBSOIL DATA UNDER UNION BAY

\begin{tabular}{|lccc|}
\hline Medium & $\begin{array}{c}\text { Average Unit } \\
\text { Weight } \\
\text { (pcf) }\end{array}$ & $\begin{array}{c}\text { Compressional } \\
\text { Wave Velocity } \\
\text { cp (fps) }\end{array}$ & $\begin{array}{c}\text { Dynamic Modulus of } \\
\text { Elasticity } \\
\text { E(psi) }\end{array}$ \\
Peat & 63.7 & 500 & $300-800$ \\
Soft Clay & 100. & $3000-3600$ & $3000-10,000$ \\
Medium Clay & 110 & $4600-7300$ & Not available \\
Stiff Clay & 128 & & \\
Till & 135 & & \\
\hline
\end{tabular}




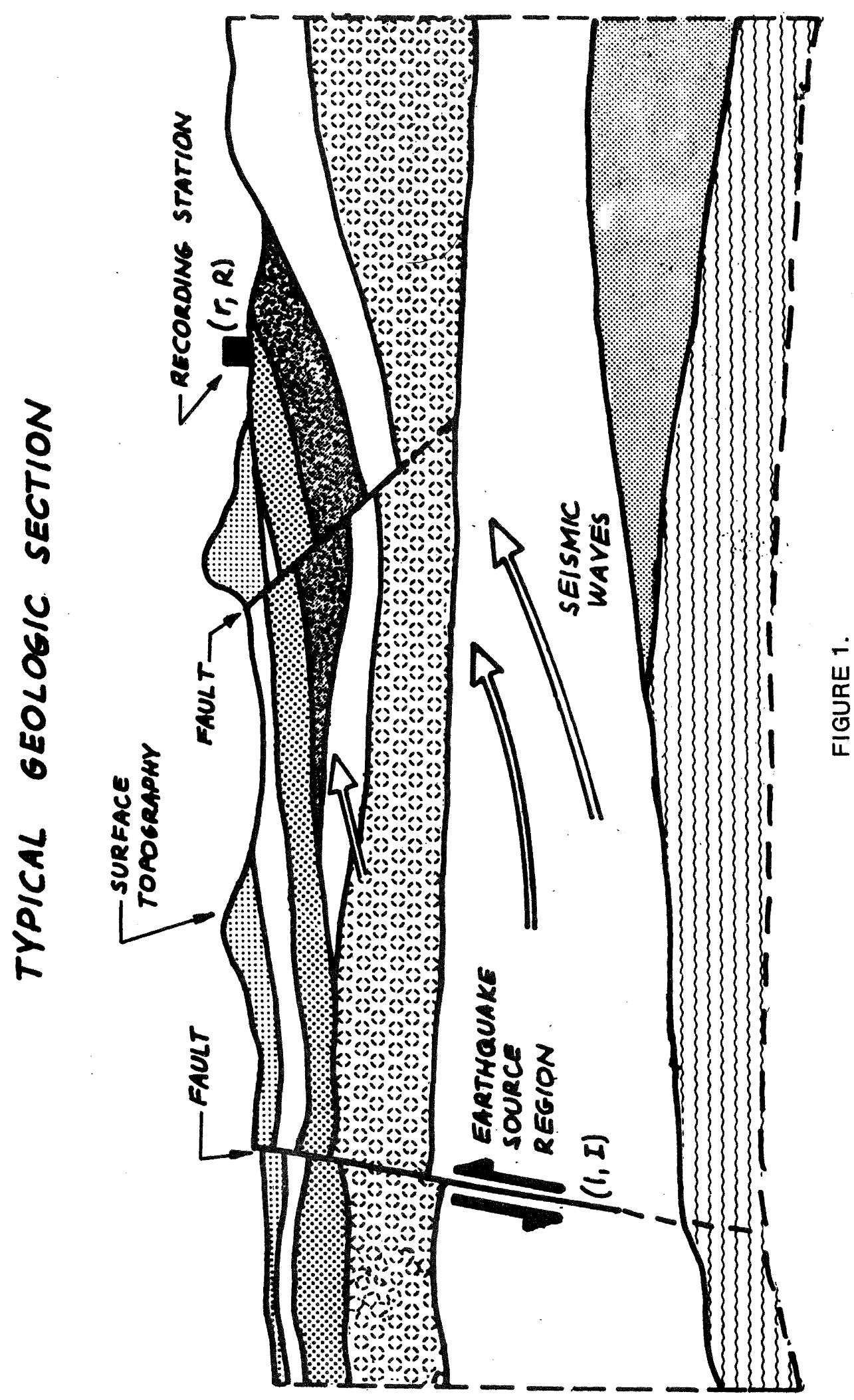




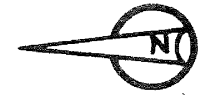

$$
\begin{gathered}
\text { CLAY TILL } \\
0 \text { O }{ }^{\circ} \\
\text { PEAT }
\end{gathered}
$$

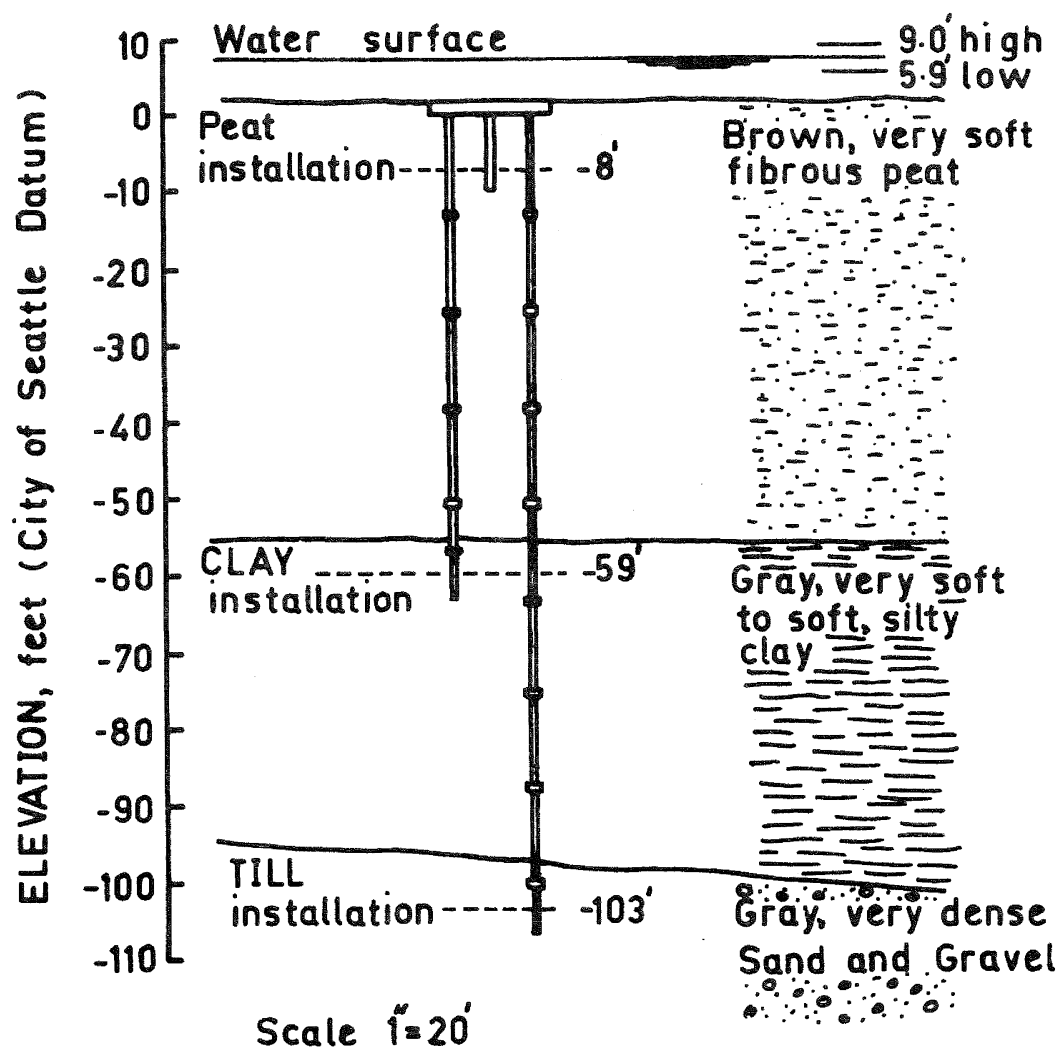

FIGURE 2. GEOLOGICAL PROFILE UNDER UNION BAY

ELEV.

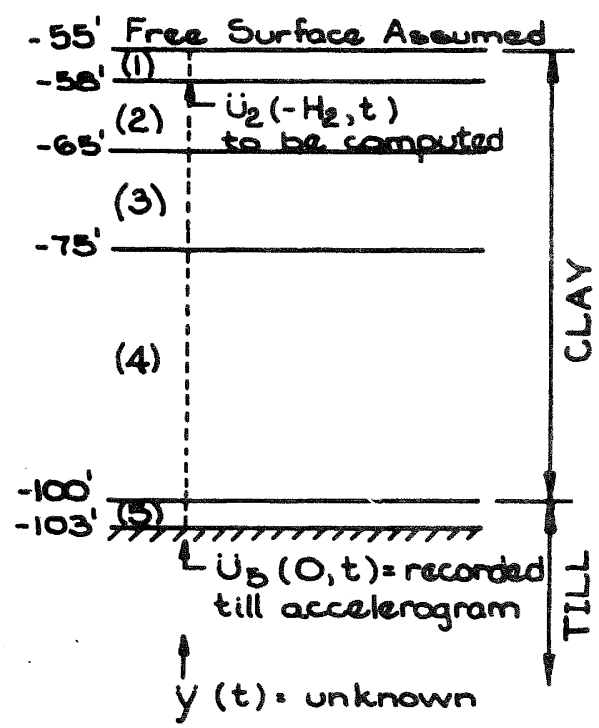

\begin{tabular}{|c|c|c|c|c|c|}
\hline & & & & & \\
\hline & & & & & \\
\hline & 3 & 100 & 205 & & \\
\hline & $\overline{7}$ & 105 & 205 & 220 & 30 \\
\hline & 16 & 115 & & 50 & 575 \\
\hline & & & 60 & $\$ 50$ & 4 \\
\hline & & 130 & 1500 & 500 & 50 \\
\hline
\end{tabular}

LAYER PARAMETERS

FIGURE 3: THE 5-LAYER MODEL FOR THE CLAY-TILL SYSTEM UNDER UNION BAY 


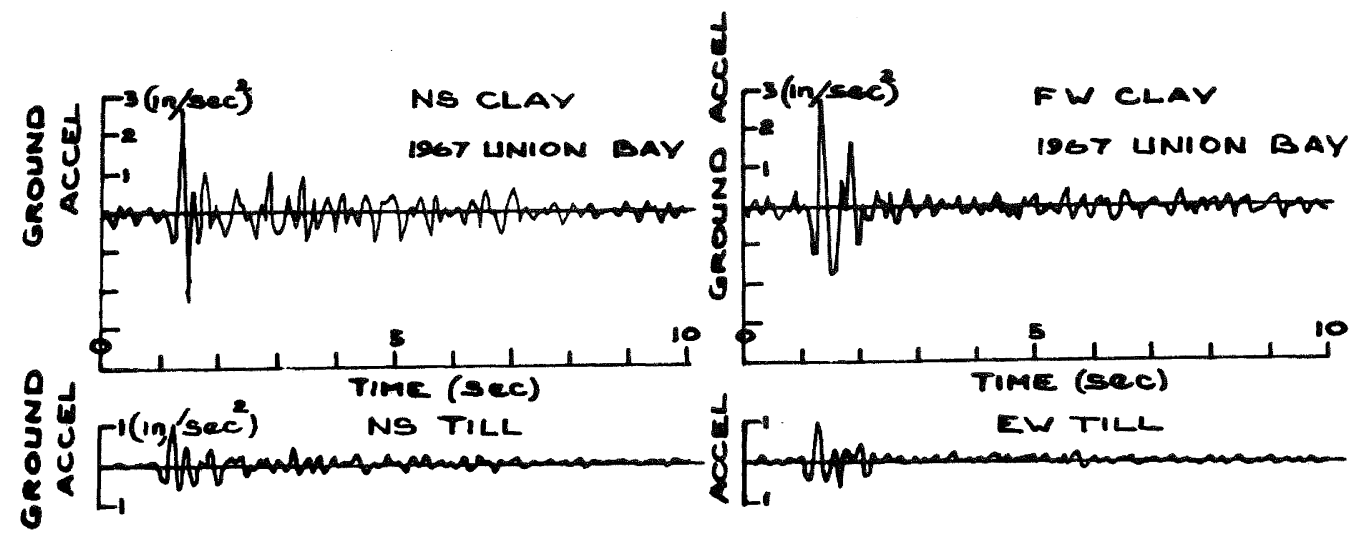

FIGURE 4: THE UNION BAY LOCAL EARTHQUAKE (1967)

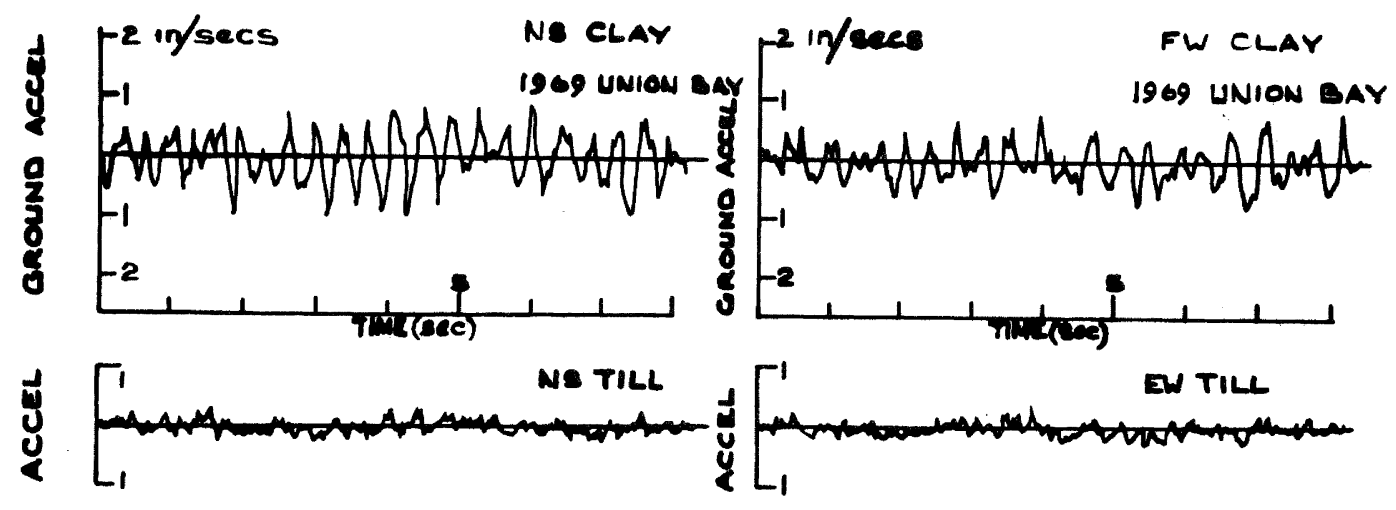

FIGURE 5: THE UNION BAY MICROTREMOR (1969)

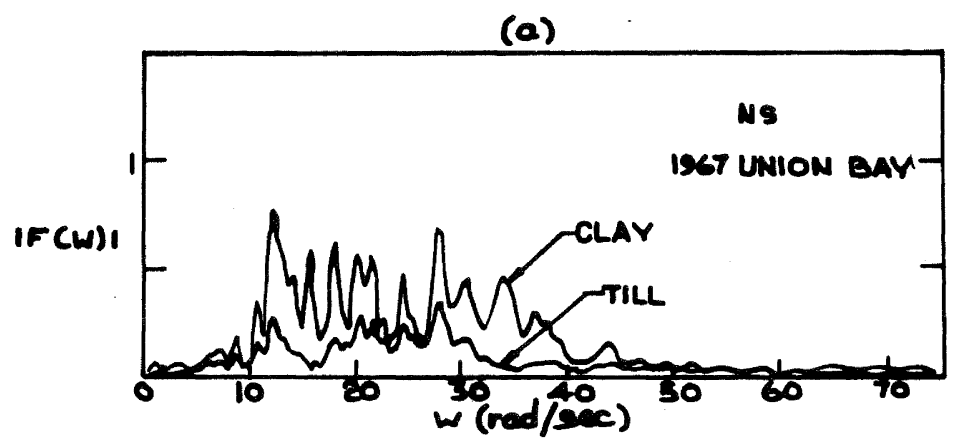

(b)

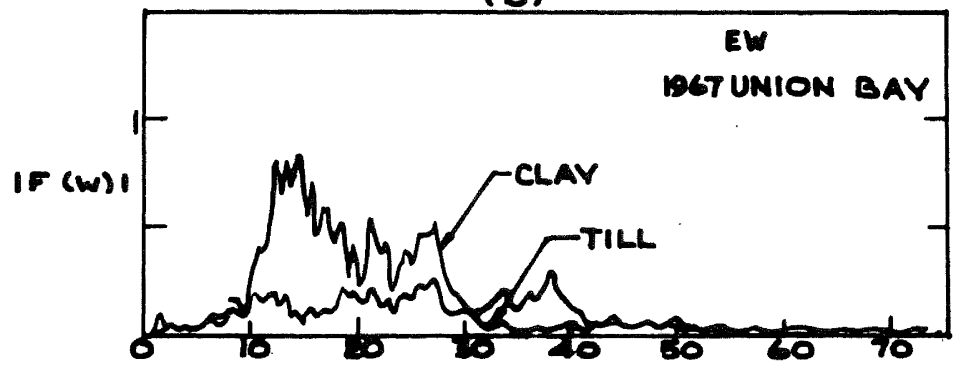

FIGURE 6: FOURIER AMPLITUDE SPECTRA (1967) ') 

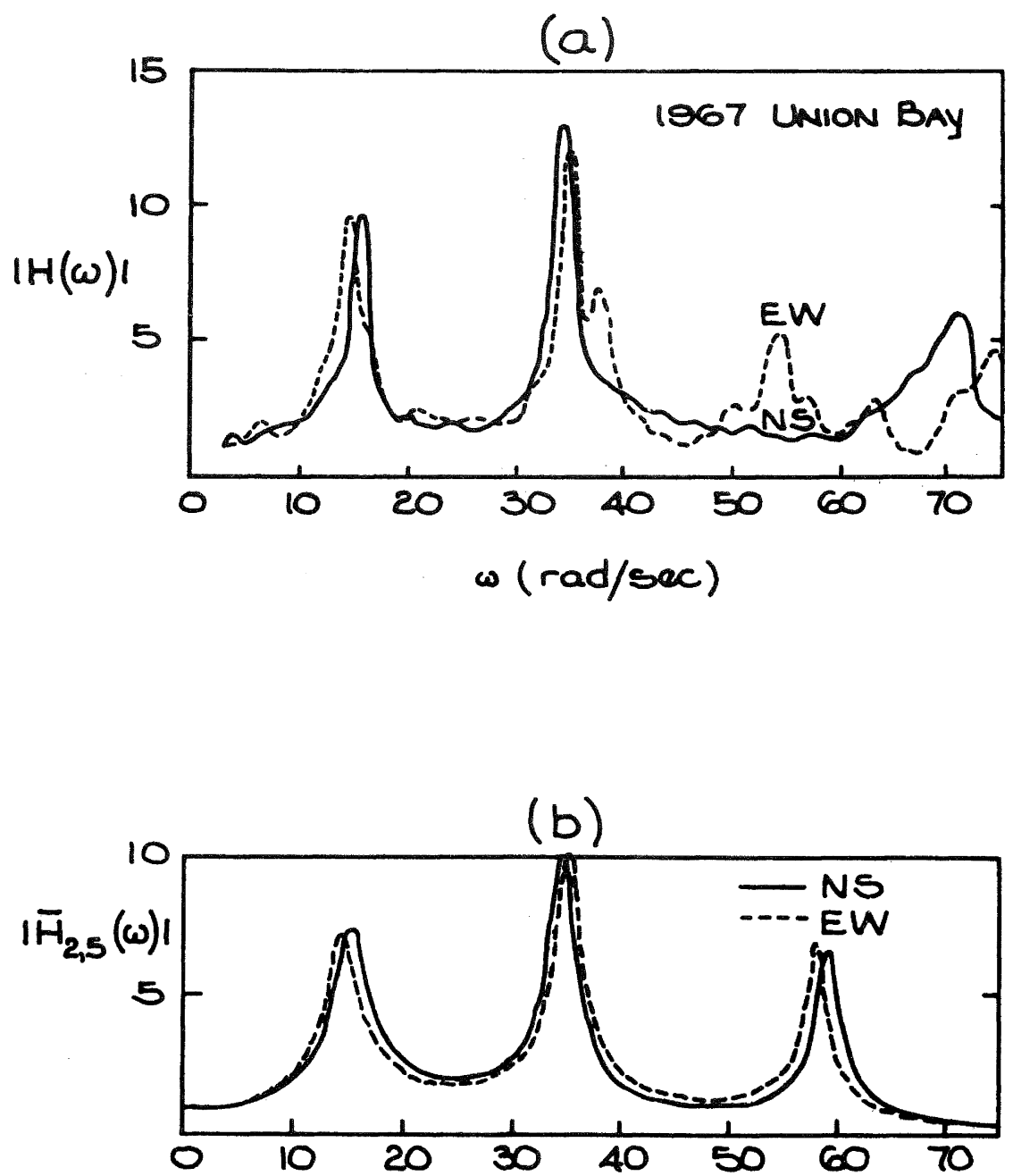

FIGURE 7: EXPERIMENTAL AND THEORETICAL TRANSFER FUNCTION OF THE CLAY-TILL SYSTEM (1967).

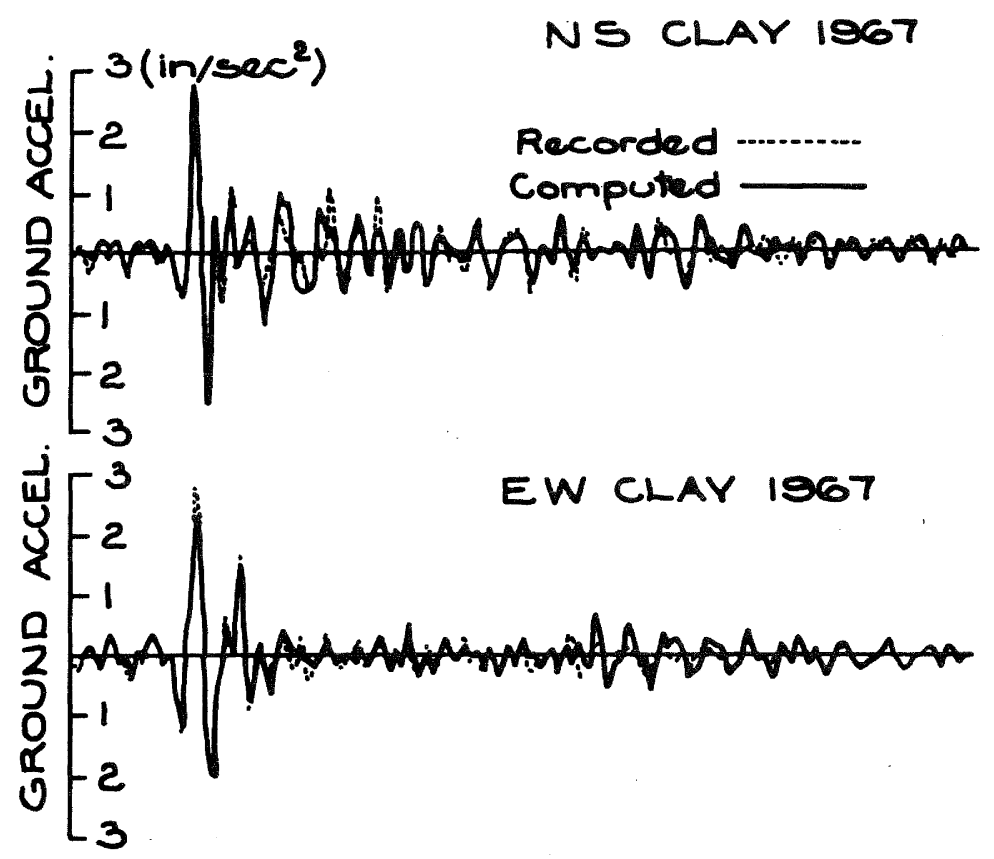

FIGURE 8: COMPUTED CLAY MOTIONS (1967) 
71

(a)

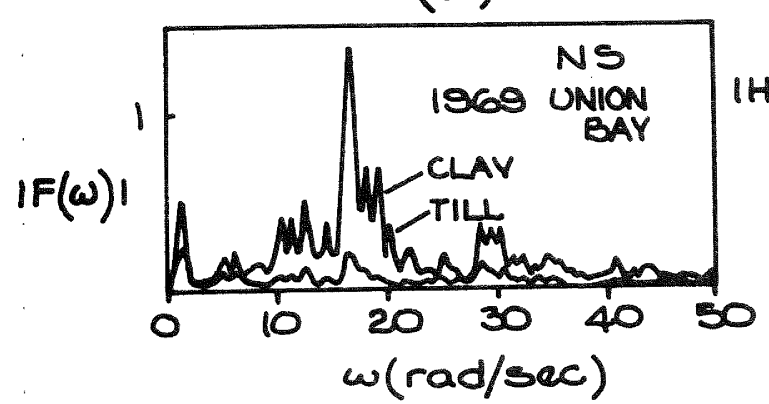

(c)

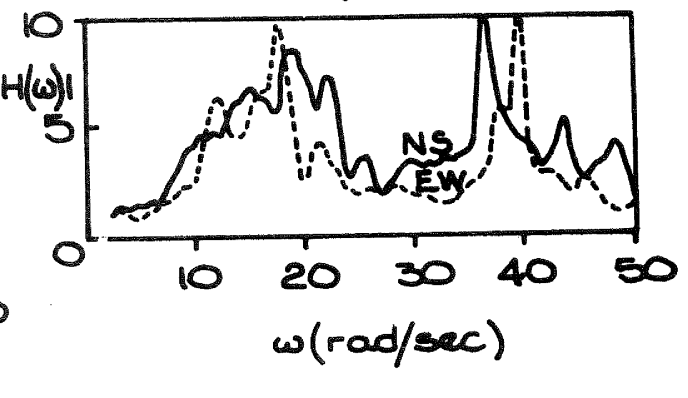

(d)

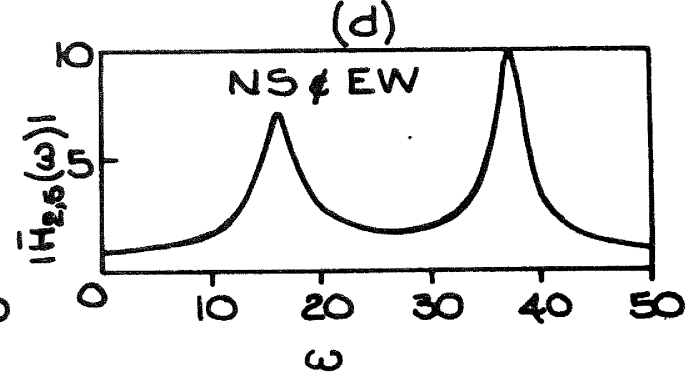

FIGURE 9: FOURIER AMPLITUDE SPECTRA AND TRANSFER FUNCTIONS OF THE CLAY-TILL SYSTEM (1969).

NS CLAY 1969

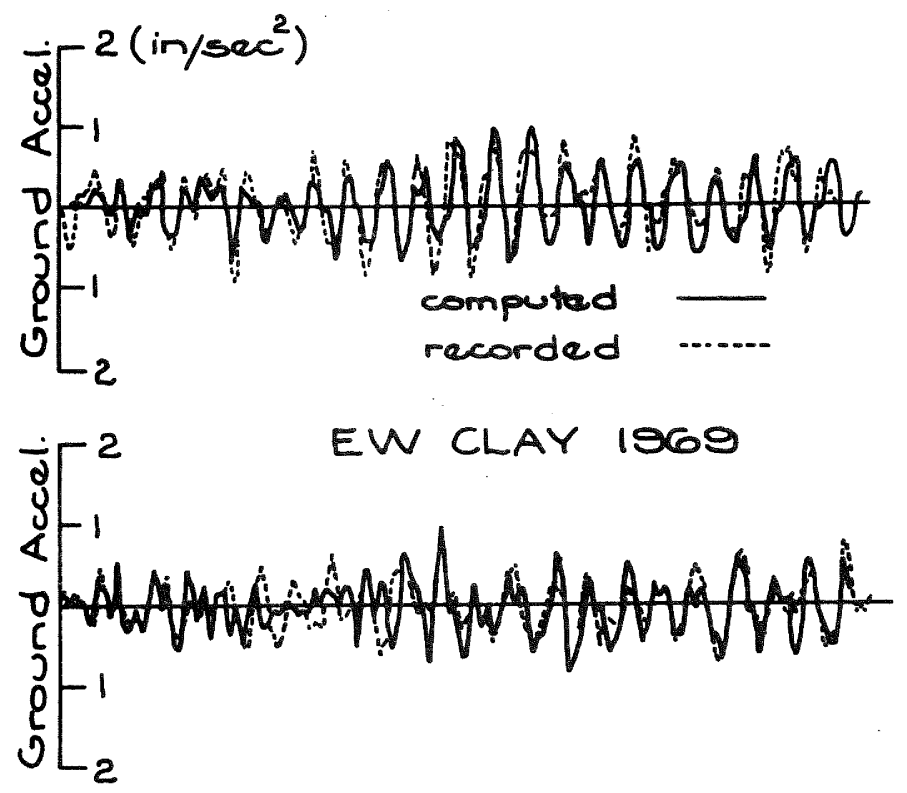

FIGURE 10: COMPUTED CLAY MOTIONS (1969). 

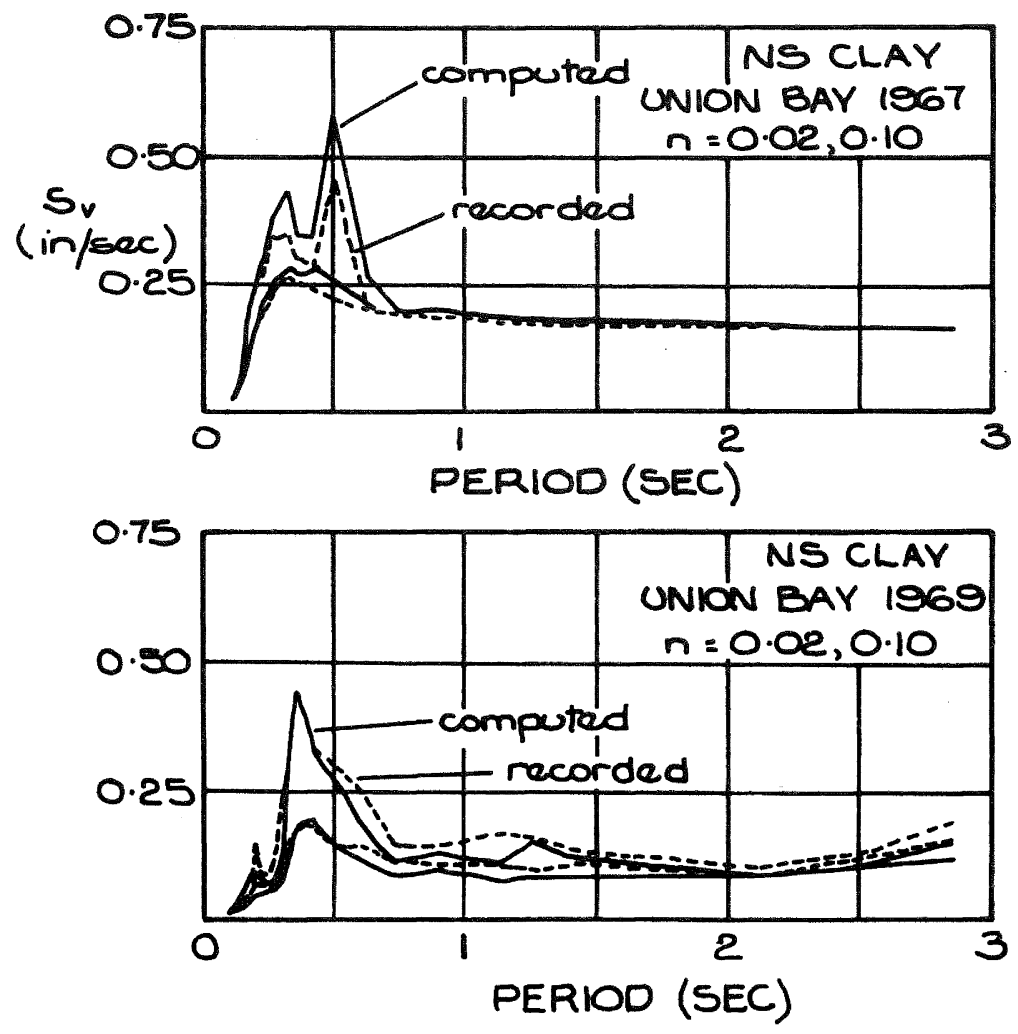

FIGURE 11: RESPONSE SPECTRA OF THE CLAY MOTIONS

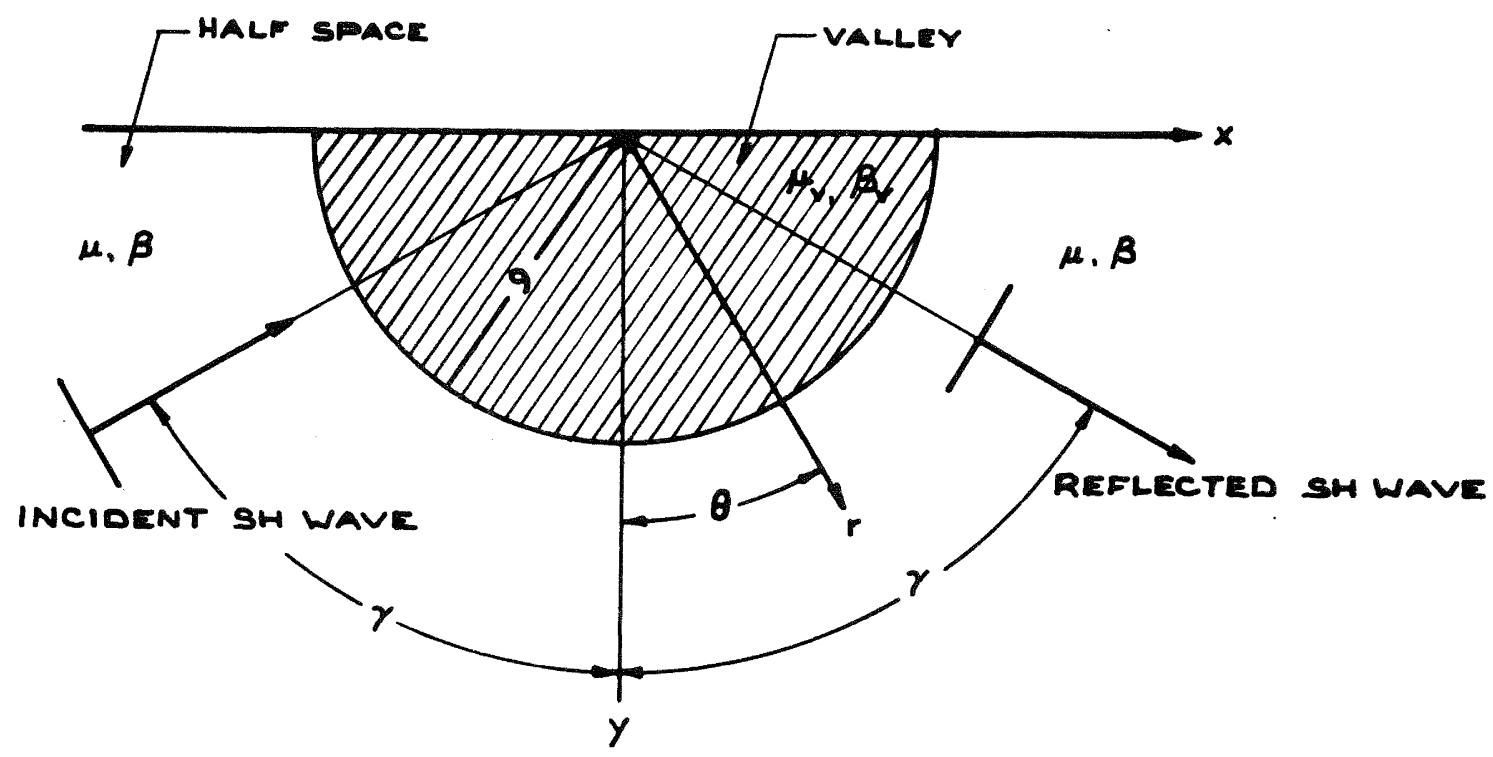

FIGURE 12: SEMI-CYLINDRICAL VALLEY AND THE SURROUNDING HALF-SPACE. 

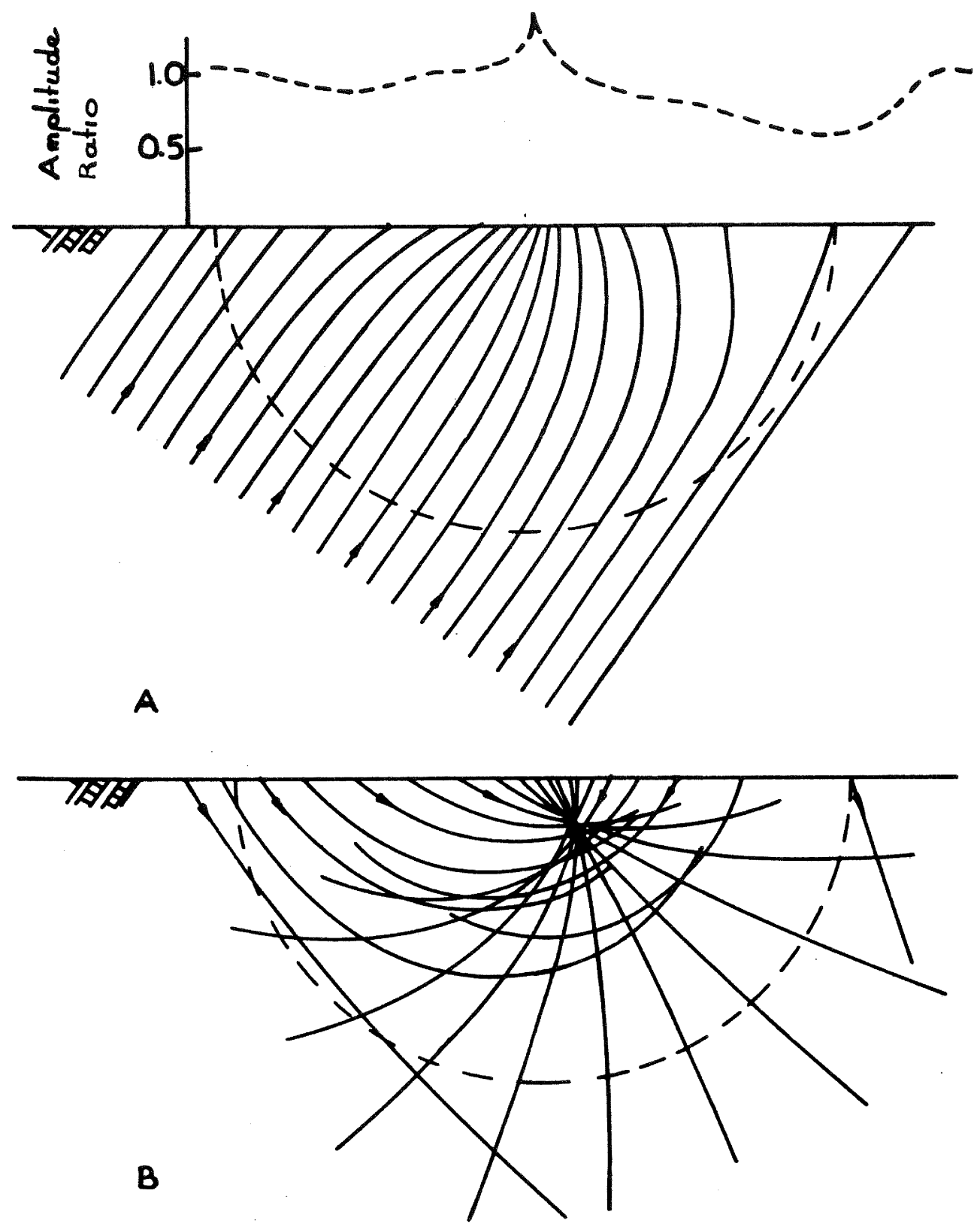

FIGURE 13: THE FORMATION OF A CUSPED.

A, INCIDENT SV WAVES;

B, REFLECTED SV WAVES. 


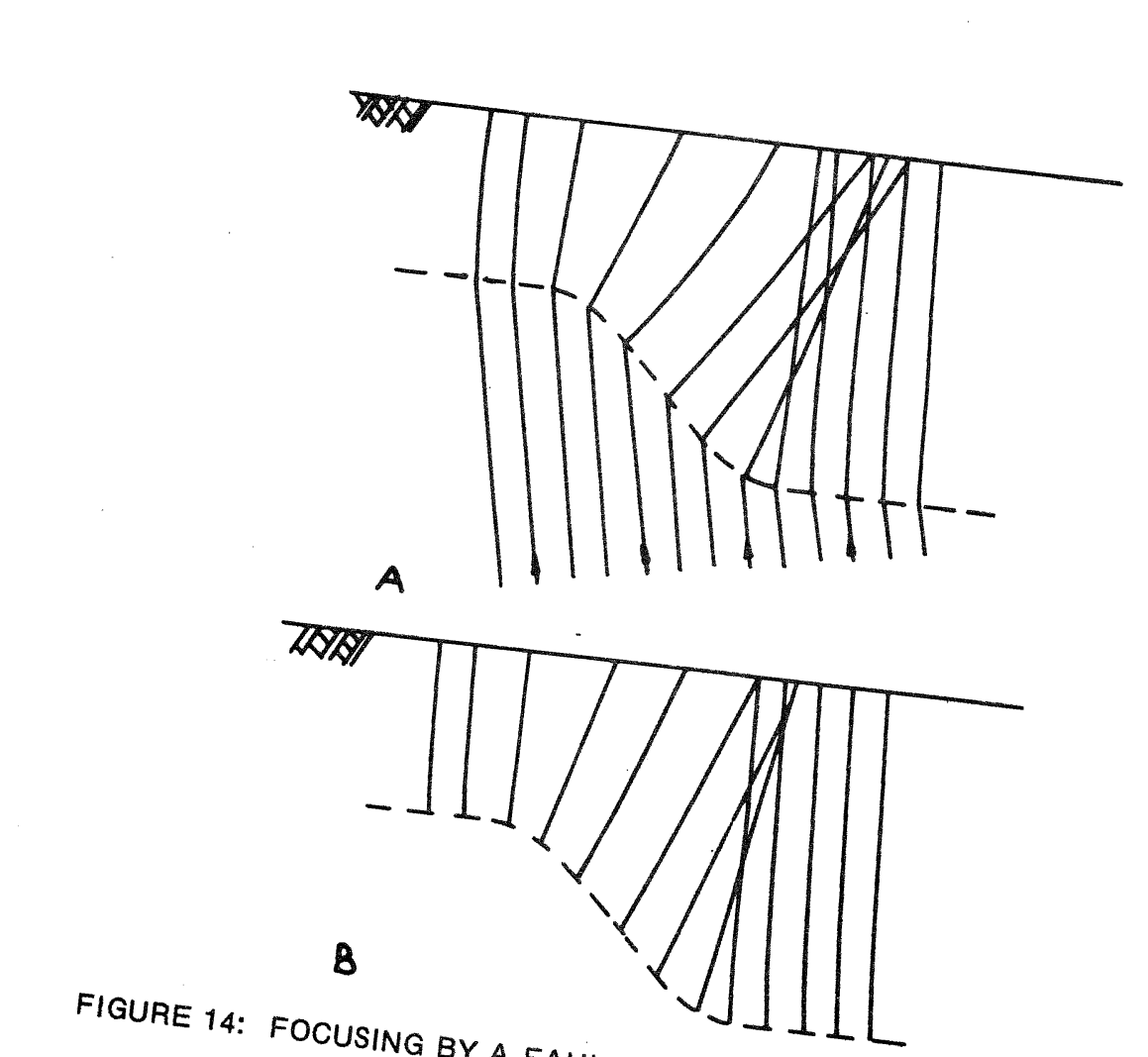

FIGURE 14: FOCUSING BY A FAULT (SKOPJE) A.
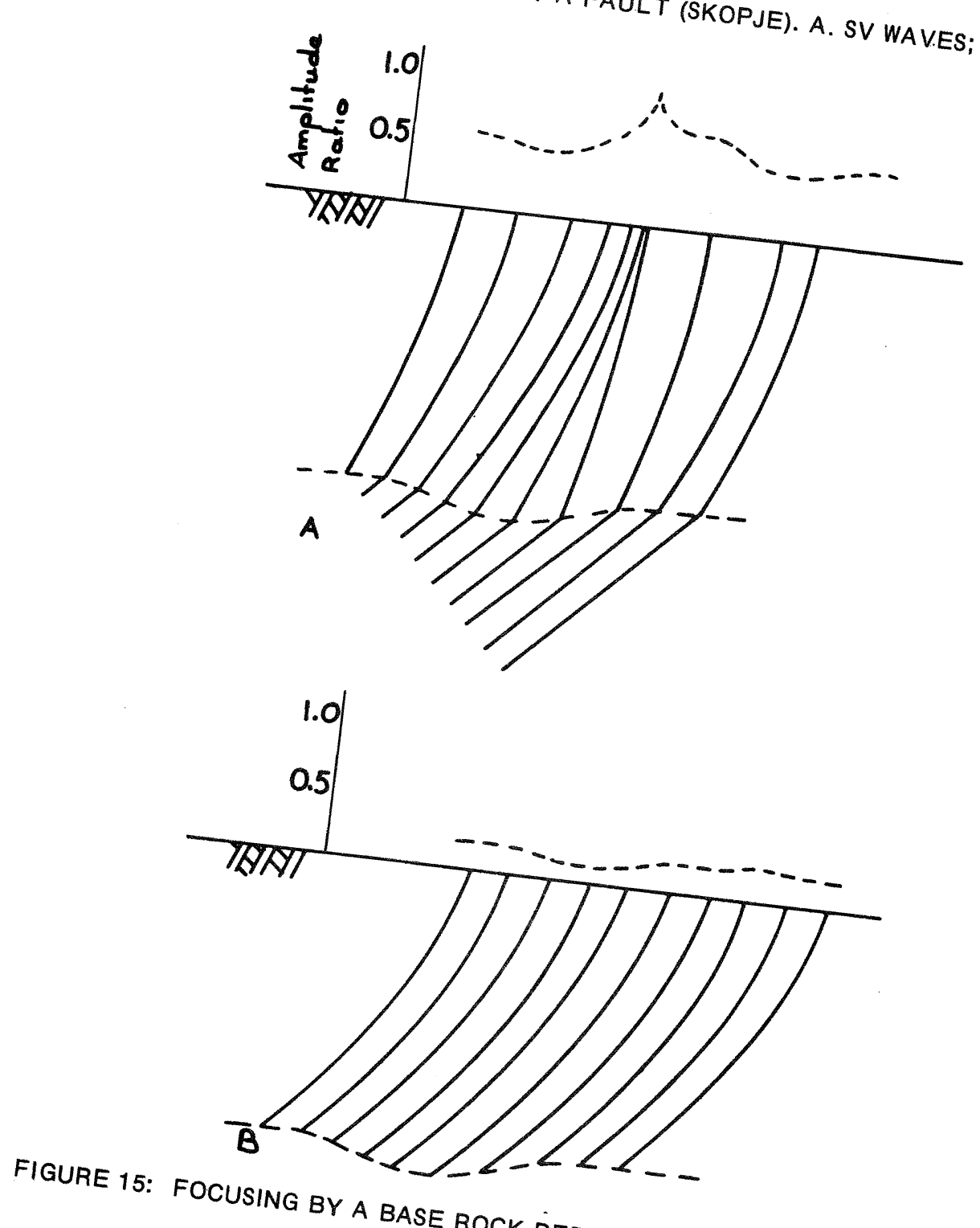

FIGURE 15: FOCUSING BYA BASE ROCK DEDDF

ION. A, SV WAVES; B, P WAVES. 

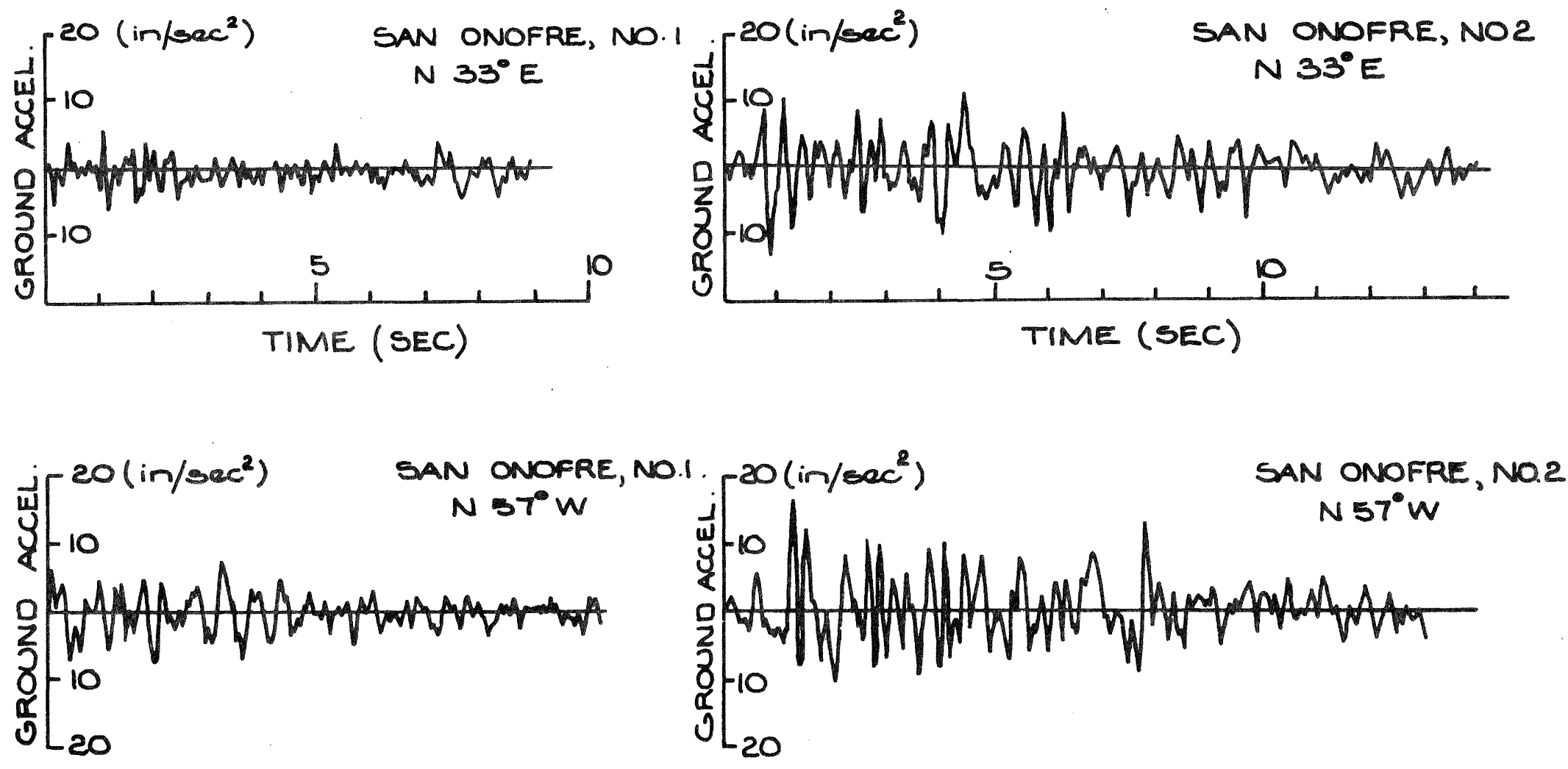

FIGURE 16: THE TWO SHOCKS OF THE BORREGO MOUNTAIN EARTHQUAKE RECORDED AT SAN ONOFRE, 9 APRIL 1968. 

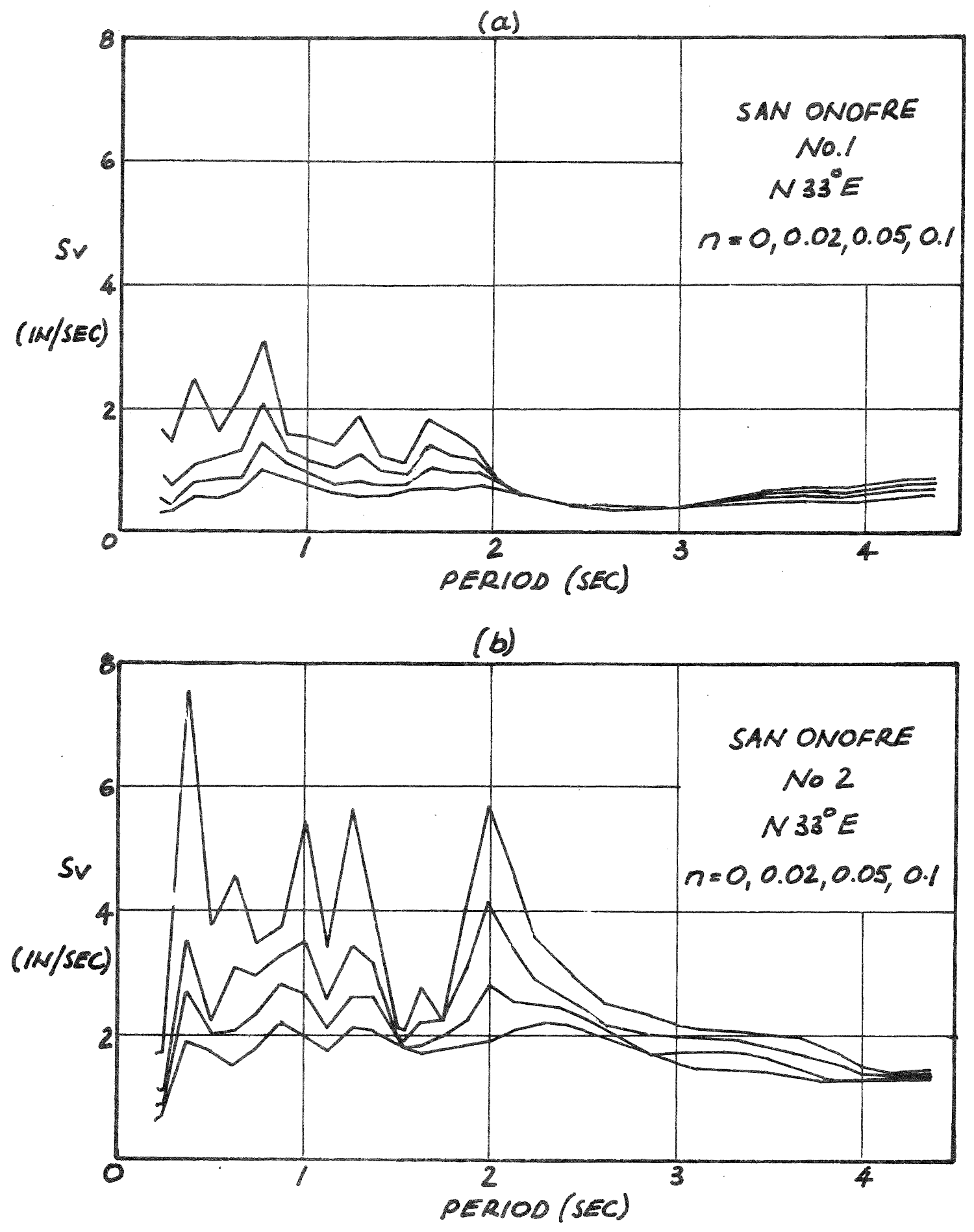

FIGURE 17: VELOCITY SPECTRA FOR THE SAN ONOFRE SHOCKS (N33 ${ }^{\circ} \mathrm{E}$ ). 

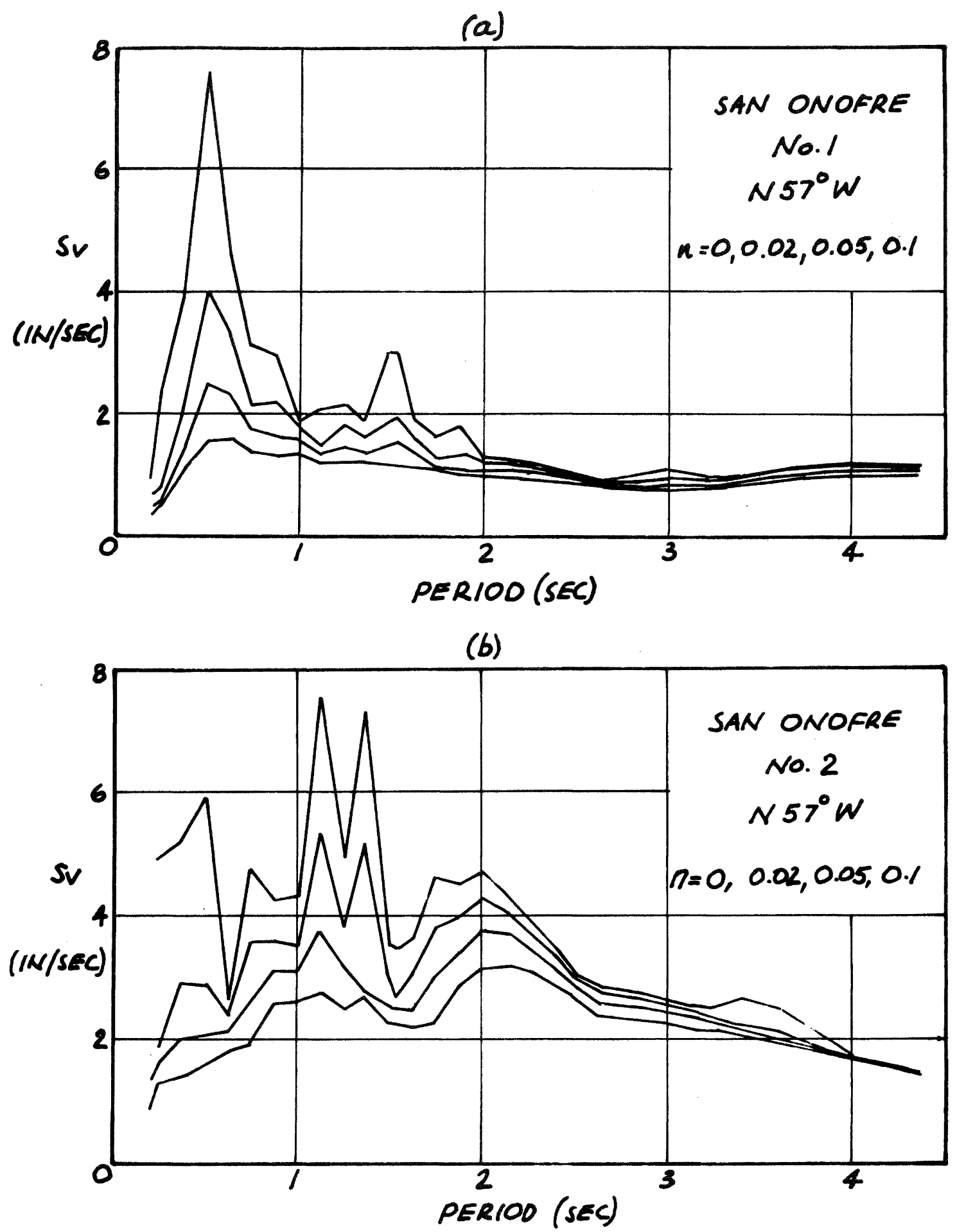

FIGURE 18: VELOCITY SPECTRA FOR THE SAN ONOFRE SHOCKS (N57'W). 